\title{
Primitive ants (Hymenoptera: Sphecomyrminae) in the Campanian (Late Cretaceous) of North Carolina (USA) ${ }^{1}$
}

\author{
Victor E. Krynicki ${ }^{2}$
}

\begin{abstract}
A small amber piece containing one nearly complete and four partial winged male fossil ants was collected from a lignite layer at a site along the Neuse River near Goldsboro, North Carolina, USA. Based on the anatomical details, these ants belong to the extinct subfamily Sphecomyrminae. While a formal species description and naming is not the purpose of this paper, similarities are noted to the ant genera Sphecomyrma and Baikurus, and taxonomic identification is made with the latter: Baikurus. This finding confirms the presence of the subfamily Sphecomyrminae in the Campanian stage and adds North Carolina to a short list of worldwide sites where Cretaceous ants have been uncovered. Further, this finding provides added confirmation of the social nature of ants already in the Late Cretaceous with particular reference to swarming behavior, as this piece is the fourth discovery of multiple winged males in amber.
\end{abstract}

Key Words: amber, Cretaceous, Hymenoptera, ant, Sphecomyrminae, Sphecomyrma, Baikurus, social behavior, Neuse River, North Carolina, USA

In the early years of the twentieth century, paleobotanist Edward Berry described amber pieces from lignite beds along the Neuse River in the region of Goldsboro, North Carolina (Berry 1907). Since that initial publication, the scientific literature has only occasionally mentioned plant fossils and amber from this area. In a compendium on North Carolina fossil sites, Locality 34 in Goldsboro is described as a Cretaceous Black Creek Formation exposure along the Neuse River that yields lignitized and silicified wood as well as rare amber (Carter et al. 1988). A lignitized fossil fruit, Grexlupus carolinensis Mickle (Lauraceae) was discovered at this Upper Cretaceous, Campanian stage (approximately 83.6 to $72.1 \mathrm{Ma}$, million years ago) site (Mickle 1996). However, this publication does not mention the presence of amber in the lignite layer. Amber is of significant paleontological interest since it can contain biological inclusions that exquisitely document life in the past. Amber from North Carolina analyzed with nuclear magnetic resonance spectroscopy (NMR) belongs to class A, likely a coniferous source, or to class B, perhaps produced by members of the Dipterocarpaceae (Lambert et al. 2002, 2012).

Currently, based on sheer numbers, ants (Formicidae) are likely the most dominant insect family worldwide. Thus, understanding their origin and evolution is important to paleontologists (Grimaldi et al. 1997; Wilson and Holldobler 2005). Ants embedded in Cenozoic Era amber (65 million years old or younger), particularly those from Miocene (approximately 23.03 to $5.33 \mathrm{Ma}$ )

\footnotetext{
${ }^{1}$ Submitted on September 12, 2013. Accepted on September 22, 2013. Final revision received on September 25, 2013.

${ }^{2}$ Finish Line Road, Bahama, North Carolina 27503-9657. USA. E-mail: vkrynicki@nc.rr.com
}

DOI: 10.9784/LEB1(3)Krynicki.03

Electronically available on September 30, 2013. Mailed on October 12, 2013. 
amber, are relatively common. However, Cretaceous ants in amber are rare (Barden and Grimaldi 2013). Cretaceous ants are stem-group taxa and many of these possess unique physical features that distinguish them from modern groups. The oldest known ants are approximately 100 million years old and were found in amber from Myanmar and France (Barden and Grimaldi 2013, Perrichot et al. 2008). Most Cretaceous ants have been placed in the subfamily Sphecomyrminae, a subfamily characterized by the presence of a metapleural gland and a generally low-rounded petiole, combined with absence of the elbowlike bend in the antennae (due to a short scape, or first antennal segment) that is found in modern ants (Barden and Grimaldi 2013).

Cretaceous ants in amber have been found at a number of worldwide locations, but only at two North American sites: the Cliffwood Beach/Sayreville, New Jersey region in the United States, and Alberta, Canada (Perrichot et al. 2008). Finding additional North American specimens is significant in defining the types and distribution of ancestral ant species during the Late Cretaceous.

\section{Methods}

In 2012, amber was collected by the author from lignite beds at Locality 34 identified by Carter et al. (1988). All collected pieces were prepared by washing and cleaning off the lignite, and were then examined for inclusions using a Unitron ZSB microscope. One amber piece contained multiple ants including several that were breaking out of the amber's surface. Therefore, standard shaping and polishing techniques using a progressively finer series of sandpaper grits was not possible as this approach would damage the insects that were already at and/or protruding through the surface. Instead, the amber's surface was buffed with a 4000 grit pad to improve clarity and the surface was coated in clear epoxy. This method represents a faster and simpler version of the more difficult resin block embedding technique (Grimaldi et al. 1997). The surface epoxy coating method serves the same purposes of strengthening fragile amber, preventing further surface breakage, and clarifying the surface. While further preparation and preservation may be required in the future, the amber piece is currently stable.

After allowing several days for epoxy drying, the piece with ant inclusions was re-examined with a dissecting photomicroscope equipped with an OptixCam Summit camera. To provide improved tridimensional details and depth of field, individual photos were digitally combined using a digital image stacking software (Helicon Focus, a product of Helicon Soft Ltd., Chippenham, Wiltshire, England, UK). Anatomical details that were examined included: number of antenna segments, scape to pedicel ratio, eye shape, wing venation, number of tibial spurs, petiole and gaster shape, and petiole dimensions. 


\section{Results}

The amber piece contained six partial to nearly complete male ants. However, one of these was an isolated, poorly preserved head that lacked taxonomically relevant details and was not considered a viable inclusion for analysis. Therefore, the five better preserved male ants were the only ones examined. Figure 1 shows Ants 1, 2, and 3, while Figure 2 shows Ants 4 and 5. Additional figures (Figures 3 - 6) show close-up views of various specimens relevant to their analysis. All specimens appear to be from the same species. The following summarizes key observations for each ant.

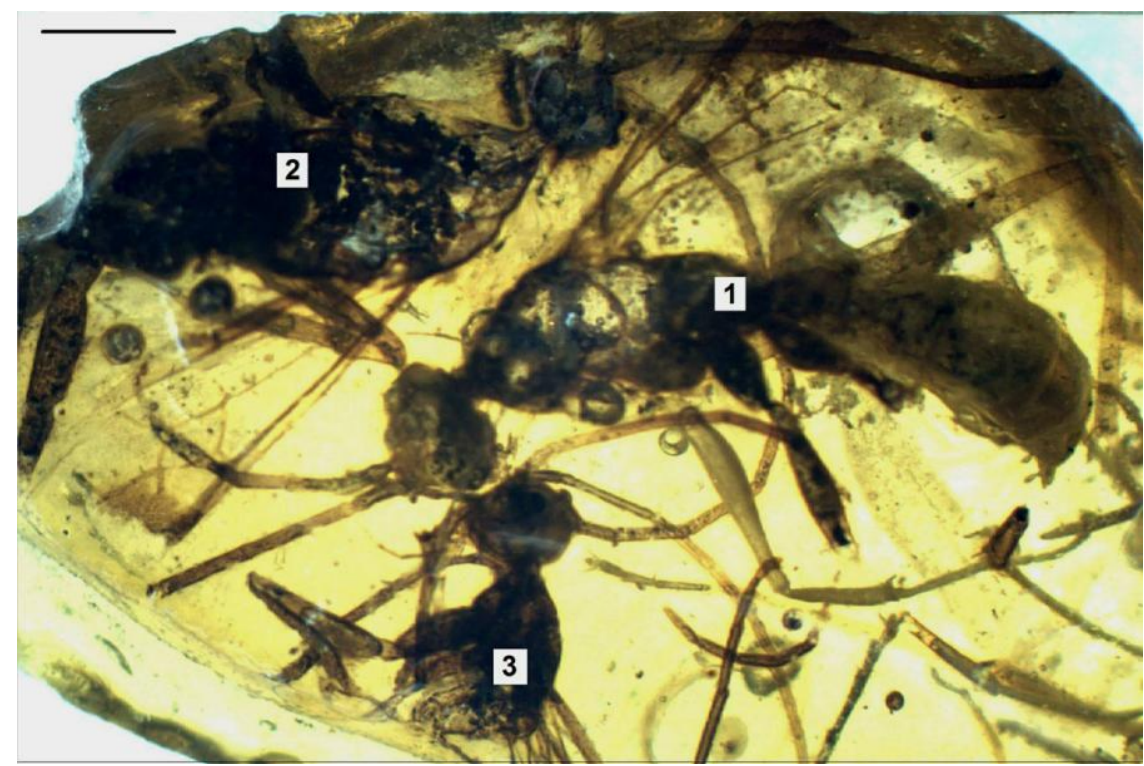

Figure 1. Ants 1, 2, and 3. Ant 1 is nearly complete, but its dorsal alitrunk breaks out of the amber; the anterior and mid-section of ant 2 are mostly complete, but its gaster is almost totally missing. Ant 3 is completely missing just below the area of the wing attachment. Scale bar $=1 \mathrm{~mm}$.

Ant 1. This ant is nearly complete but the dorsal alitrunk breaks out of the amber and only the first four antennal segments are present. The forewing can be seen up to the pterostigma; the hindwing is indistinct. The body is mildly curled (5.5. mm long, excluding antennae and legs), making measurements difficult. Figure 3 shows the head of ant 1 , as well as that of ant 3 . The head has some obscuring verlumung (whitish byproduct of organic decay), which obscures the mandibles. The mandibles appear to be long and simple, lacking obvious teeth. Compared to the size of the head, the eyes are large and oval. There are three large ocelli located dorsally. No setae are present on the head. 


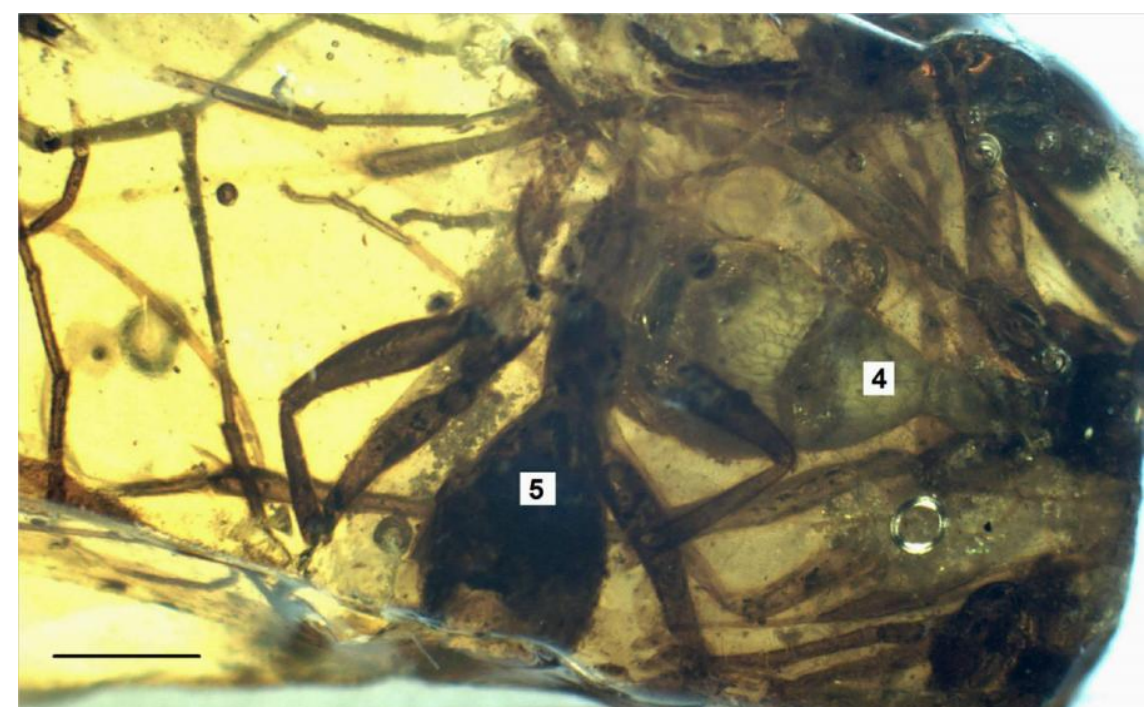

Figure 2. Ants 4 and 5. Only the petiole and most to all of the gaster are present in these two ants. Scale bar $=1 \mathrm{~mm}$.

The scape, the first antennal segment, is relatively short $(0.37 \mathrm{~mm})$. The scape is about $0.45 \mathrm{X}$ the length of flagellomere 1 , or antennal segment 3 ( 0.8 $\mathrm{mm})$, and this is characteristic of ancestral ants. The pedicel, or second antennal segment, is tiny $(0.15 \mathrm{~mm})$, about $0.4 \mathrm{X}$ the length of the scape. One short labial palp is present with four visible segments. Next to the palp's terminal segment there is another terminal segment, which is apparently all that remains of the second labial palp.

The alitrunk is poorly preserved. The dorsal section breaks the amber surface and the ventral section appears faint and shadowy. Viewed from above, the left foreleg is complete, the left midleg is nearly complete (missing the posterior femur and anterior tibia), and the left hindleg is nearly complete (missing most of femur and the tibial base). The foreleg has one tibial spur, the midleg has two, and the hindleg has one visible spur, but obscuring debris likely hides a second spur. The right-sided legs are nearly complete but faintly preserved and difficult to see. The right foreleg is complete to the end of the tibia and has one tibial spur; the midleg is complete with one visible tibial spur, and the hindleg is complete with two spurs. The forewing is present to the pterostigma. Its venation is generally unclear, but the coastal or $\mathrm{C}$ vein appears to reach the pterostigma. 


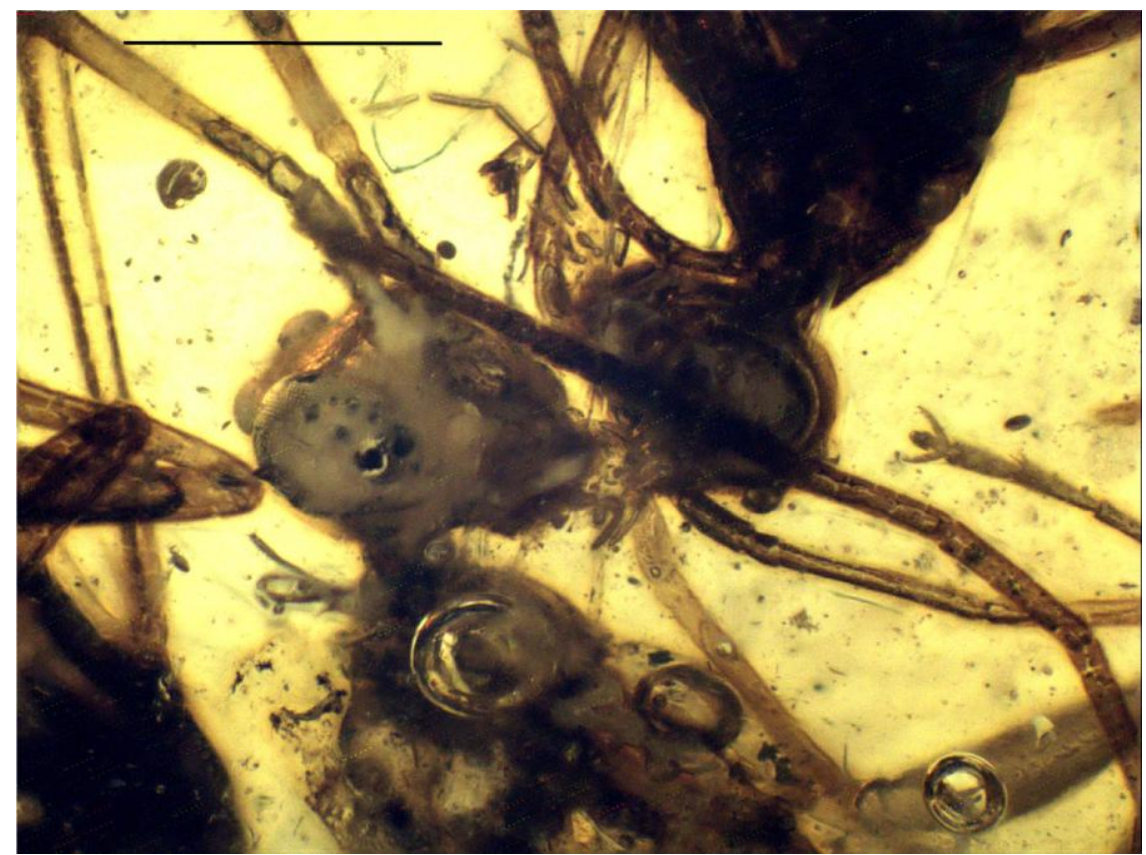

Figure 3. Anterior view of ant 1 and lateral view of ant 3. Ant 1 has large oval eyes with ocelli on the dorsal area of the head; the short scape, very short pedicel, as well as flagellomere 1 are visible. One short palp and a second partial palp are visible in front of its mandibles. Ant 3 has two pairs of palps that are broken away from and lying in front of its head. Scale bar $=1 \mathrm{~mm}$.

Figure 4 shows ant 1's posterior region. A metapleural gland opening near the hind coxa is not evident either by microscopic observation or in the photograph. The presence of a metapleural gland opening is characteristic of female worker ants but not winged male ants. The petiole is about $2 \mathrm{X}$ as long as wide $(0.8 \mathrm{~mm}$ to $0.42 \mathrm{~mm})$, slender, and relatively cylindrical, without a notable apical protuberance. The gaster is curled, making measurement difficult (estimated to be about $2.3 \mathrm{~mm}$ long). Its first segment is roughly equal to the length of the petiole. Bristle-like setae are seen ventrally on the gaster near its terminus. The terminus is pointed, with bilobed genitalia.

Ant 2. The dorsal and left side of the head are missing (broken out of the amber), and the dorsal alitrunk is also missing. One antenna loops around to Ant 1 and is complete, while the other is mostly complete but very difficult to observe as it runs along the edge of the amber. The complete antenna has 13 segments (11 flagellomeres) but some segmental divisions are indistinct. The presence of 13 segments is consistent with most male hymenopteran insects. 


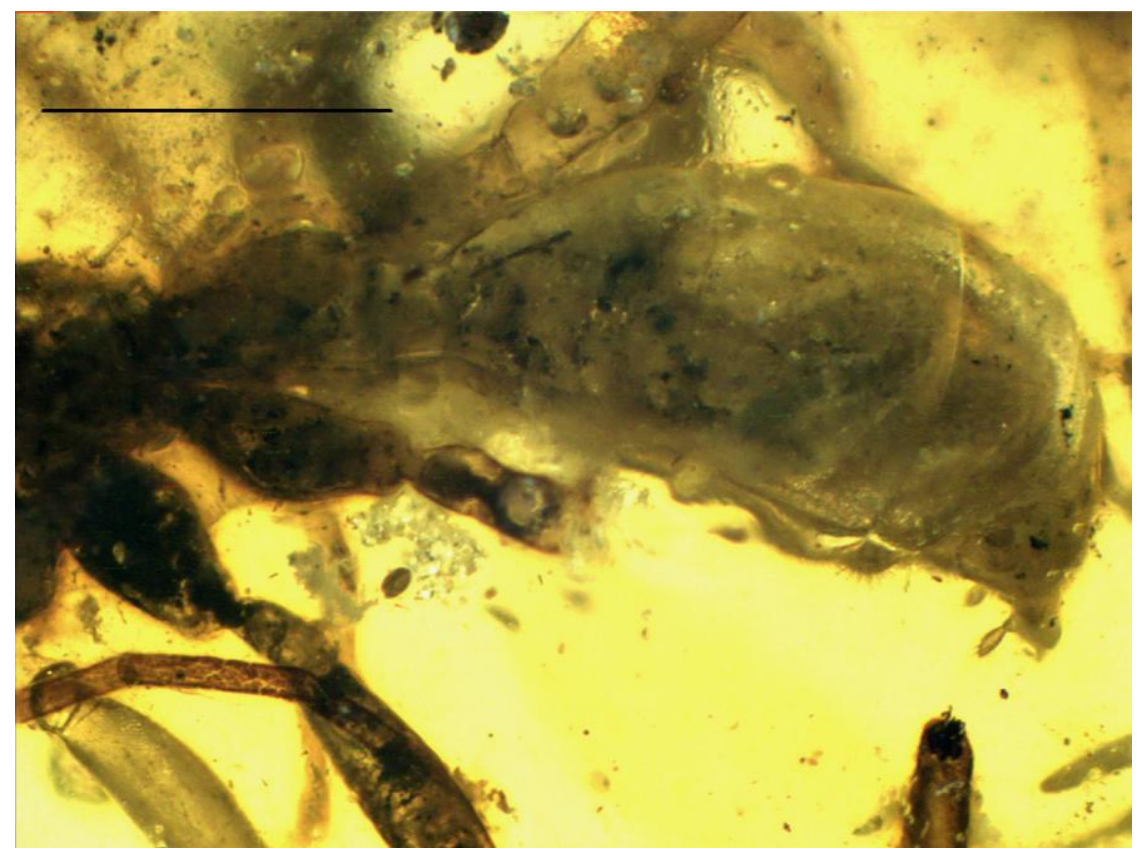

Figure 4. Posterior view of the abdomen of ant 1 . The petiole is long and slender, about twice as long as wide. The gaster has a pointed terminus, with genitalia visible. Scale bar $=1 \mathrm{~mm}$.

Figure 5 shows ant 2's partial forewing (the hindwing is unclear), which is estimated to be about two-thirds complete. The pterostigma is visible and vein $\mathrm{C}$ reaches the pterostigma. Other aspects of the wing venation are very similar to those of Baikuris mandibularis Dlussky, 1987 and to the Sphecomyrma ant identified as NJ-242 (Grimaldi et al. 1997).

The petiole of ant 2 is complete but only a miniscule portion of the gaster is present. Three legs are largely complete while the other three are broken away at the upper femur. The foreleg is held close to the body, with one tibial spur barely visible against the dark background. The nearly complete midleg has two tibial spurs, while the hindleg is missing the area (tibial-tarsus junction) where spurs are located. Figure 6 depicts this ant's midleg with its two tibial spurs.

Ant 3. The head and most of the alitrunk are present, but the body beyond this point is missing. Only a small wing portion is present. One antenna is mostly complete, with ten segments present. The other antenna is missing most of its segments. One foreleg is mostly present and has one tibial spur, and all other legs are missing. Of all specimens, ant 3 has the best preserved palps: two pairs are visible, with some separations between segments. The labial pair is short with 4 segments, while the maxillary pair is long with 5 segments. 


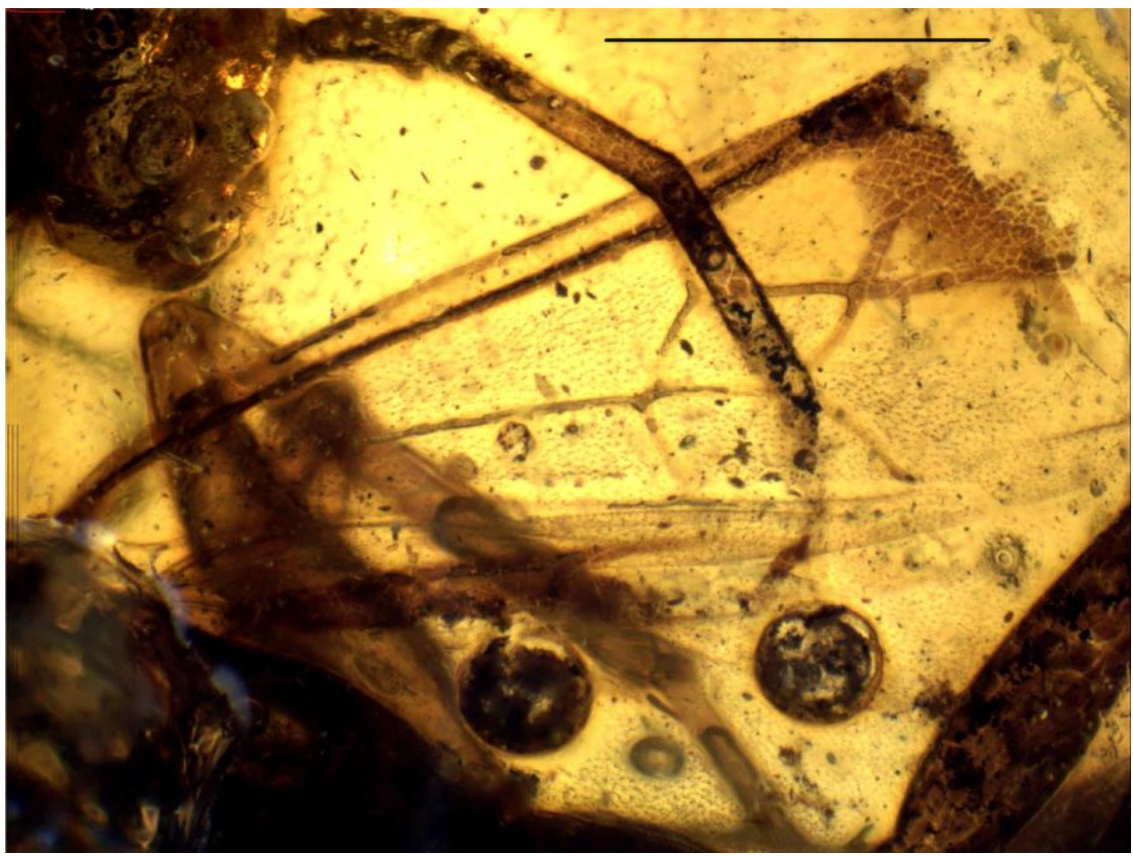

Figure 5. Partial forewing of ant 2. The pterostigma is visible. The venation is quite similar to species of Siberian Baikurus and to species of Sphecomyrma. However, the vein pattern differs from $B$. casei. Scale bar $=1 \mathrm{~mm}$.

Ant 4. A tiny end segment of the metasoma is present, while the petiole and gaster are complete. Five complete legs are present; the sixth is missing. The forelegs have one tibial spur, both midlegs have two, but the hindlegs are inconsistent: one has one spur and the other has two. Like ant 1, the long, slender petiole is twice as long as wide $(0.79$ to $0.39 \mathrm{~mm})$, and the gaster has a similar size of about $2.4 \mathrm{~mm}$. Unlike ant 1, the gaster has a rounded terminus without visible genitalia.

Ant 5. The full petiole and anterior two-thirds of the gaster are preserved, with the gaster's terminal broken out of the amber. The alitrunk is also broken out of the amber at the point of attachment to the petiole. Four partial legs are also present, consisting generally of the femur and part of the tibia.

\section{Discussion}

Perrichot et al. (2008) list eight worldwide locales where Cretaceous ants have been found, including two Early Cretaceous and six Late Cretaceous sites. Among the Late Cretaceous sites there are two in North America: Sayreville, New Jersey and Alberta, Canada. This North Carolina discovery is significant in adding the Neuse River site to a short list of worldwide locations where 
Cretaceous ants are found. The Goldsboro Black Creek Formation is Campanian in age (Mickle 1996). This is equivalent to the Campanian age of Canadian amber and somewhat younger than the Turonian age (90 to $94 \mathrm{Ma}$ ) amber of New Jersey (Perrichot et al. 2008). This may be an important period that sheds light on the continuing evolution of ant subfamilies, as this amber is slightly younger than the ambers providing the first examples of ancestral subfamilies (Grimaldi and Agosti 2000).

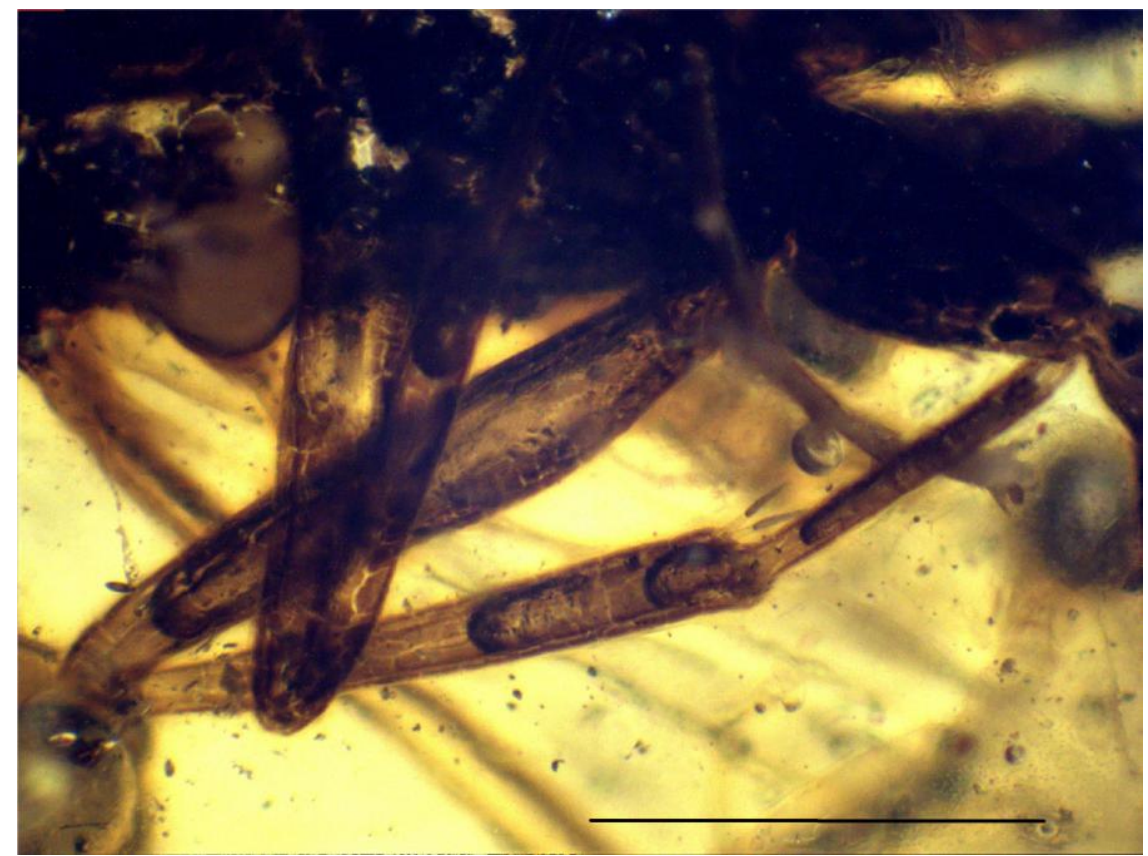

Figure 6. Midleg of ant 2, with foreleg overlapping. Two tibial spurs appear at the tibialtarsus junction. Its forewing is located in the background (out of focus). Scale bar $=1$ $\mathrm{mm}$.

The North Carolina specimens appear similar to both Baikurus and Sphecomyrma. Baikurus ants were first identified from Siberian amber deposits, and Siberian species include B. mandibularis Dlussky and B. mirabilis Dlussky. Only males were found and they have kidney-shaped eyes, narrow mandibles, a distinctive forewing vein pattern, and two tibial spurs on every leg (Dlussky 1987). After Dlussky's report, Grimaldi et al. (1997) identified the species $B$. casei Grimaldi, Agosti, and Carpenter, 1997 from New Jersey amber, with a complete and a partial male seen in one amber piece. The complete male (holotype) ant has oval (not kidney-shaped) eyes with very similar genitalia to both Siberian Baikurus species. There are three large ocelli dorsally. Antennae have 13 segments, and labial palps are long while maxillary palps are shorter. 
The legs are long and slender; the forelegs have one apical tibial spur and the mid- and hindlegs have two spurs. In the forewing, vein $\mathrm{C}$ does not reach the pterostigma. The petiole of the holotype is $2.3 \mathrm{X}$ its width and the petiole's shape is relatively cylindrical without a notable apical protuberance.

Sphecomyrma ants were first identified in New Jersey Cretaceous amber, and a typical example is AMNH NJ-242 (Grimaldi et al. 1997). This is a winged male ant with kidney-shaped eyes and three large ocelli on the vertex of its head. While there are thirteen antennal segments, the scape is approximately the same size as flagellomere I. In the forewing, vein $\mathrm{C}$ reaches the pterostigma. The forelegs apparently have no tibial spur, while the mid- and hindlegs each have a pair of spurs. The petiole is humped, with an apical protuberance on its dorsal side.

Overall, the North Carolina Cretaceous ants have similarities to both Baikuris and Sphecomyrma. The North Carolina specimens have oval eyes, three large ocelli on the dorsal head, 13 antennal segments, and scape and pedicel dimensions (pedicel about $0.4 \mathrm{X}$ the length of scape) closely matching $B$. casei. Unlike B. casei (but similar to other species of Baikuris and Sphecomyrma), vein $\mathrm{C}$ reaches the pterostigma. Compared to both Baikuris and Sphecomyrma, there are some differences in palp length and/or number of segments. For example, B. casei has long labial and short maxillary palps, which is the reverse of the North Carolina specimens.

There are variations in tibial spur counts amongst the North Carolina ants: all ants have only one spur on the forelegs (where preserved) but vary between one and two spurs on the mid- and hindlegs. While individual variability is possible, this is most likely due to incomplete preservation and obscuring debris. Where preservation is best, a 1-2-2 spur pattern is seen in the North Carolina specimens. Grimaldi et al. (1997) report no spurs on the front legs of their Sphecomyrma and a 1-2-2 pattern on the holotype of B. casei.

Finally, the cylindrical petiole, gaster, and the genitalia of the North Carolina specimens are similar to those of B. casei. Overall, the North Carolina ants possibly represent a new species of Baikuris, but I am currently studying the specimens further with the intention of formally describing them.

The North Carolina specimens also reveal early ant social and/or colony behavior. The multiple winged ants in the amber piece likely represent the colony behavior known as a "flying ant day." Entrapment in resin likely occurred when queen ants emerged for their nuptial flight, with male ants flying alongside them. Interestingly, this activity has been observed in at least three other Cretaceous specimens: Russian (Dlussky 1987), Burmese (Anderson 2009), and North American B. casei specimens, with two males reported in amber piece AMNH NJ-90 (Grimaldi et al. 1997). Thus, this North Carolina amber specimen provides added confirmation that the group behavior of ancestral ants was a worldwide phenomenon in the Late Cretaceous. 


\section{Acknowledgements}

I thank Scott Anderson for his critical reading of the manuscript and for his helpful comments and suggestions.

\section{Literature Cited}

Anderson, S. R. 2009. A primitive ant brood chamber with evidence of brood care in Burmese amber (Lower Cretaceous) - implications for brood care as the facilitating factor for true eusociality and dominance of ants. Denisia $26: 11-20$.

Barden, P. and D. Grimaldi. 2013. A new genus of highly specialized ants in Cretaceous Burmese amber (Hymenoptera: Formicidae). Zootaxa 3681: 405 - 412. http://dx.doi.org/10.11646/zootaxa.3681.4.5

Berry, E. W. 1907. Contributions to the Mesozoic flora of the Atlantic coastal Plain-II. North Carolina. Bulletin of the Torrey Botanical Club 34: $185-206$. http://dx.doi.org/10.2307/2479239

Carter, J. G., P. E. Gallagher, R. E. Valone, and T. J. Rossbach. 1988. Fossil Collecting in North Carolina. Bulletin 89. Department of Natural Resources and Community Development, Raleigh, N.C.

Dlussky, G. 1987. New Formicoidea (Hymenoptera) of the Upper Cretaceous. Paleontological Journal 21: $146-150$.

Grimaldi, D, and D. Agosti. 2000. A formicine in New Jersey Cretaceous amber (Hymenoptera: formicidae) and early evolution of the ants. Proceedings of the National Academy of Sciences 97: 13678 - 13683. http://dx.doi.org/10.1073/pnas.240452097

Grimaldi, D., D. Agosti, and J. M. Carpenter. 1997. New and rediscovered primitive ants (Hymenoptera: Formicidae) in Cretaceous amber from New Jersey, and their phylogenetic relationships. American Museum Novitates 3208: 1 - 43.

Lambert, J. B., Y. Wu, and J. A. Santiago-Blay. 2002. Modern and ancient resins from Africa and the Americas. Chapter 6, pp. 64-83. In, Archaeological Chemistry. Materials, Methods, and Meaning. Symposium Series No. 831. K. A. Jakes (Editor). American Chemical Society. Washington, District of Columbia, USA. $261 \mathrm{pp}$.

Lambert, J. B., C. Y.-H. Tsai, M. C. Shah, A. E. Hurtley, and J. A. Santiago-Blay. 2012. Distinguishing amber classes by proton magnetic resonance spectroscopy. Archaeometry 54(2):332-348. http://dx.doi.org/10.1111/j.1475-4754.2011.00625.x

Mickle, J. E. 1996. Grexlupus carolinensis, a new probable lauraceous fruit from the late Cretaceous of North Carolina. Journal of the Elisha Mitchell Scientific Society 112: 1-6.

Perrichot, V., S. Lacau, D. Neraudeau, and A. Nel. 2008. Fossil evidence for the early ant evolution. Natrwissenschaften 95: 85 - 90. http://dx.doi.org/10.1007/s00114-007-0301-8

Wilson E. O. and B. Holldobler. 2005. The rise of the ants: a phylogenetic and ecological explanation. Proceedings of the National Academy of Sciences USA 102:7411-7414. http://dx.doi.org/10.1073/pnas.0502264102 